\title{
Relationship of Abusive Supervision and Creativity of Academic Staff in Public Sector Universities: Mediating role of Knowledge Sharing
}

Sana Asghar ${ }^{1}$, Sobia Sultana ${ }^{1 *}$

\begin{abstract}
The importance of knowledge management enhances the competitive advantage of an organization in today's knowledge-based economy is agreed upon. In this era of globalized economy, knowledge is the main driver for growth. Knowledge promotes creativity is proved in the extant literature which is effected by abusive supervision. In this present study, we examine the process through which abusive supervision affects the creativity of employees. In particular, with the likelihood that abusive supervision is related to creativity of the employees and mediated by knowledge sharing behavior. Thus, the aim of present study is to investigate the effect of abusive supervision on the creativity of academic staff in the public sector universities with the mediating role of knowledge sharing. In order to analyze the relationship among the variables involved in the study, utilized the quantitative research methodology, deductive approach and cross-sectional time horizon .The questionnaire survey technique was adopted to collect the data. A five-point Likert scales with significant measures was used. The targeted population of the present study was the academic staff of three universities (Lahore College for Women University, The University of the Punjab, and Government College University, Lahore). Total 330 employees were selected as a sample through utilizing the proportionate stratified random sampling technique and among them 298 was fit for the analysis. The statistical tool, SPSS and AMOS was utilized to analyze the collected data to obtain the results. The results of the study show that abusive supervision has a negative effect on employee creativity and knowledge sharing of employees whereas; knowledge sharing has significant positive effect on employee creativity. Though, knowledge sharing is partially mediating the relationship between abusive supervision and knowledge sharing.
\end{abstract}

Keywords: Abusive supervision, Creativity, Knowledge sharing, public sector universities.

\section{Introduction}

In 1947, when Pakistan was established, the educational resources allocated to West Pakistan in the form of established institutions were very small, compared to the resources allocated to India. Although in both developed and developing countries, it is a fact that the performance of educational institutions depends on their ability to attract, https://doi.org/10.30537/sijmb.v4i2.110

${ }^{1}$ Lahore College for Women University, Lahore, Pakistan

* Corresponding Author: sobia.hassan@lcwu.edu.pk 
retain and maintain their academic staff. Knowledge management has been perceived as essential segments for the survival of institutions. Employees who hold knowledge can be utilized to enhance knowledge advancement and can influence information. The exchange of knowledge is a process of sharing thoughts, facts and information and is a useful interaction of people. It is an activity where people exchange knowledge and create a new one. Knowledge sharing enhances creativity among employees due to mutual sharing of information. Creativity is the development of innovative and functional ideas about products and services; processes and actions and become more fundamental for the continued existence and competition of today's organizations. Employee creativity is facilitated by supervisory support, feedback and self-efficacy and inhibited by abusive supervision in organizations.

It is generally perceived that education is the most capable force in reducing poverty, raising financial development, delivering talented human assets, making solid and illuminated social conditions and creating self-sufficient organizations. According to Noordin and Jusoff (2009), institutions can satisfy their academic staff through wellorganized working conditions because the expectations of society depend on the success of the higher education system and this educational system becomes more successful due to the effort, support and participation of academic staff. It is not unbelievable that organizations are struggling to create a viable knowledge management considering the ultimate goal of encouraging people to share their knowledge(Pais \& Santos, 2015). Knowledge management is fundamentally based on making accurate knowledge. Therefore, knowledge sharing is the most substantial stage of the procedure. French, Raven, and Cartwright (1959) Stated that knowledge is measured as a basis of power. However, few studies have investigated the effect of practices that may decrease employee knowledge sharing behavior .People do not generally share their knowledge and they will not share as much as the organization might want from them. According to (Bock, Zmud, Kim, \& Lee, 2005; Ryhammar \& Brolin, 1999) the academic institutions tends to depend more on the exchange of knowledge, but surprisingly very few studies have examined the objective of sharing knowledge of academic staff in higher education.

In today's innovation-driven economy, creativity is the key to expand the competitive advantage through which firm can sustain in the speedily fluctuating surroundings. Employee creativity has been preserved very necessary for the persistence and competition of the organizations (Shalley, Zhou, \& Oldham, 2004). Creativity refers to the creative capacity to start or create new thoughts and ideas.

The specified objectives of the current research study were as follows:

- To find out the relationship between abusive supervision and employee creativity in public sector universities

- To investigate the effect of abusive supervision on knowledge sharing

- To investigate effect of knowledge sharing on Employee Creativity 
- To study the mediating role of knowledge sharing among abusive supervision and employee creativity

The current study emphasizes overcoming the study gaps, since a central part of past studies has been taken into account considering the relationship between employee creativity and innovation in the business and hospitality sector (Hon, 2013; Hon \& Lu, 2015; Janssen, 2003). These studies, however, have been directed towards the call for future researchers within different sectors. So this research has been directed according to previous studies on the relationship between abusive supervision and creativity of employees in the higher education sector that is limited(Amabile, Schatzel, Moneta, \& Kramer, 2004; Mumford, Scott, Gaddis, \& Strange, 2002).

\section{Literature Review}

\subsection{Abusive Supervision}

Tepper (2000) characterized the abusive supervision as representative's views on the degree to which his supervisors show i.e. forcefully treating verbal and non-verbal practices. Abusive supervision comprises a wide variety of practices. A supervisor who repeatedly criticizes workers against others, unduly blames the representatives, discourteous to the workers, rude and inconsiderate, unjustifiably assumes credits, shouts at workers, attacks the protection of workers or uses coercive strategies can be considered abusive (Tepper, 2000; Tepper, Duffy, Henle, \& Lambert, 2006; Tepper, Moss, \& Duffy, 2011).Martinko, Harvey, Sikora, and Douglas (2011) stated that abusive supervision is a subjective evaluation directed by the observation of subordinates; considering all aspects, it is conceivable that subordinates can see the behavior of a supervisor in different ways, but not all abusive supervision is seen. Past researchers have noticed that between $10 \%$ to $16 \%$ workers frequently experience abusive supervisors (Duffy, Ganster, \& Pagon, 2002; Namie \& Namie, 2009).In addition, abusive supervision offers rise to authoritative insufficiency, nonpresence and turnover.In this way, abused employees who cannot expect a sufficient level of substantial or elusive assets from their abusive supervisors will likely have low levels of shared knowledge. Mackey, Frieder, Brees, and Martinko (2017) Find out the antecedents and outcomes of abusive supervision by using psychometric correction.

\subsection{Knowledge Sharing}

Knowledge is a necessary power for learning organizations in current globalization. It is assumed that knowledge is appreciated in institutions to manage and maintain position in the market. Fundamentally, knowledge is identified with learning employees. They are people who have knowledge, great capacity, competence and are extremely bright in business. The role of the knowledge worker in the institution fosters the issues that depend on a choice, methodologies, business instructions and rivalry among other businesses. This implies that knowledge management among workers generates learning conditions, discussions, administration and undetectable advantage

Sukkur IBA Journal of Management and Business - SIJMB | Volume 4 No. 2 July - December 2017 @ Sukkur IBA University 
for institutions. The need to monitor knowledge more adequately is necessary to adapt to changes in a focused situation. The progression requires the availability of changes from both mental and auxiliary measurements for knowledge acquisition, construction and exchange procedures (Rusly, Yih-Tong Sun, \& L. Corner, 2014).

Lin, Wang, and Chen (2013)argued that the interest in innovation generally does not guarantee an effective knowledge managemnt, it is relatively guaranteed that the main pillar of success responses is the willingness and responsibility of employees to participate in activities. Despite the increasing prominence of knowledge sharing practices for hierarchical intensity and market execution, few obstructions make it problematic for knowledge management to achieve the objectives and improve the aggressiveness and the inclusive benefit of the organization. Knowledge sharing demonstrates intense procedure of knowledge interchange and learning, a process that incorporates two dimensions' knowledge donating and knowledge collection (Foss, Husted, \& Michailova, 2010).

\subsection{Employee creativity}

The word creativity is derived from the Latin word "Creatus" or "Creare", means to make. So, creativity refers to the creative capacity to start or create new thoughts and ideas. Morgan (1953) Stated the broad component of the creativity is novelty. Novelty requires innovation, originality and newness. There must be something new in the idea. According to the Amabile (1996), creativity usually denotes the creation of the untested and valuable concepts through an individual and a group of persons employed together. Creativity has a vital role in the process of innovation (Serrat, 2017).

The principal of any society lies in talent and encouragement; the development of talent contains the mobilizations of cultural societies, accumulating capital through the construction of institutions, improving the quality and values that favor achievements and ideas. The results of that are achieved from the talent that can be referred to as a new idea or creativity.

Zhou and Shalley (2003) Stated that many theorists define creativity as the improvement of thoughts about objects, services, practices, and procedures which are not only novel and unique but also useful to the institutions. Accordingly, novelty and originality are two important attributes of an idea to be judged as creative. People might have queried that to be considered as creative, an idea ought to have some possessions of being novel and originality. Although novelty is just not enough, in the milieu of work creativity, an idea should contain the possession of being functional in order to be measured. Even 
though the idea which is novel, but there is lack of potential values is considered only rare but not creative.

\section{Conceptual Framework}

The research model presented below synthesizes independent variable abusive supervision towards dependent variable employee creativity, mediated by knowledge sharing respectively.

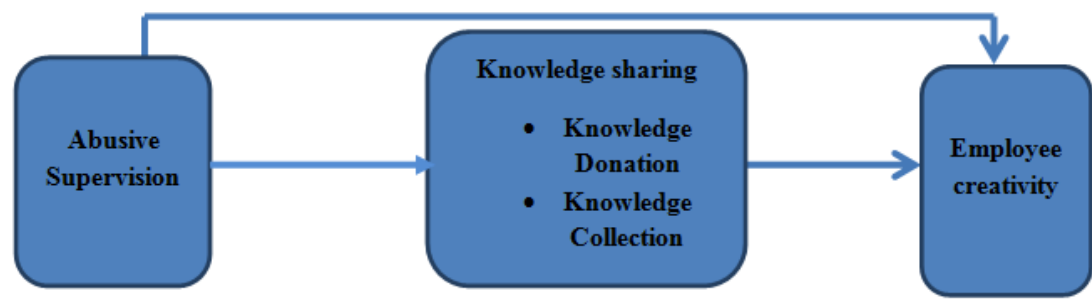

Figure 1: Conceptual Framework

The extensively held research study that has investigated the antecedents of employee's creativity, have searched that the supervisor's positive conduct is a key antecedent of employee creativity (Tierney, 2008). According to Liu, Liao and Loi (2012); Zhang, Kwan, Zhang and Wu (2014) a very few research studies have explored the impact of abusive supervision on employee creativity. They found that abusive supervision is adversely related to employee creativity, whereas other researchers found that abusive supervision takes an inverted- $u$ effect on creativity of employees. Lee, Yun, and Srivastava (2013), proposing that high or low level of abusive supervision would obstruct employee creativity, and reasonable level of abusive supervision benefit employee creativity. Subsequently, it is important to retest the association between abusive supervision and subordinates or employee's creativity.

Employees with high knowledge sharing will probably prepare their imaginative capabilities into innovative results.Wang and Noe (2010), proposed that knowledge sharing assumes an integral part in expanding employees creativity. Chang, Gong, and Peng (2012)in their studies suggested that information sharing practices could have a main effect on employees creativity. The lesser figures of studies address the issue of creativity through knowledge sharing in Pakistan's viewpoint. 


\section{Research Methodology}

Quantitative research methodology is used in this current study. In quantitative method, results are based on numbers and figures which are statistically measured and analyzed. Moreover, in the quantitative research, the hypotheses are derived through past literature support and instruments used for measurement are adopted from the past studies as well. The basic objective of this present research is to test the hypotheses that whether the employee creativity is affected by abusive supervision and either knowledge sharing mediates this relationship or not. The data has been collected through survey and different statistical test was used to analyze the data and to conclude results.

\subsection{Population}

The present study has been conducted in public sector universities of Lahore because Lahore city is famous for its academia. So it is important to evaluate the reliable sector to examine the effect of abusive supervision on creativity of academic staff or to explore the mediating behavior of knowledge sharing. In this regard we choose three renowned public sector universities as population which are University of the Punjab, Government College University and Lahore College for Women University. The logic of choosing the three institutions was that they have been providing quality education for the previous several years in different disciplines and teaching values in the young group of Pakistan.

\subsection{Sample size and data analysis technique}

In order to conduct a quantitative research, it is referred toAlreck and Settle (1985) that the sample size must be around 300. For data collection, self-administered questionnaires were used. A total of 330 questionnaires were distributed. Among them, 155 questionnaires were distributed in the University of the Punjab, 76 in Government College University and 99 in Lahore College for Women University. Total 298 questionnaires were received to be fit for analysis. Thus the actual size for analysis was 298 questionnaires that comprise of $90 \%$ response rate. Stratified propionate sampling was used in the study for questionnaire distribution and data collection.

\subsection{Hypothesis:}

H1: Abusive supervision has significant negative effect on employee's creativity.

H2: Abusive supervision has significant negative effect knowledge sharing.

H3: Knowledge sharing has significant positive effect on employee's creativity.

H4: The effect of abusive supervision on creativity is mediated by knowledge sharing.

\section{Data Analysis and Results}

Before starting the primary information investigation, information was examined for any potential missing data and amendment were made of any conceivable mistake in accumulated information. In any case, it is troublesome for a researcher to assemble an 
extensive arrangement of information with no missing qualities (Hair Jr, Black, Babin, \& Anderson, 2010). The mean score substitution method was used to replace the missing data of survey questionnaires (Tabachnick \& Fidell, 2001). Descriptive statics of demographic characteristics were employed, which includes age, gender, qualification, designation and job experience. The gender demographics show that the major part of the survey was covered by female $158(53 \%)$, whereas $140(47 \%)$ were male respondents in the survey. Moreover, the age descriptive figure represents that majority of the respondents lie in the age range of 21-30 with 124(41\%). Whereas, $109(36.6 \%)$ respondents fall in the age group of 31-40 years of age. The qualification descriptive statistics directs that majority of the respondents 188(63.1\%) hold MPhil degree whereas $77(25.8 \%)$ respondents had Ph.D. degrees. The designation descriptive statistic indicated that majority of the respondents in the survey were $160(53.7 \%)$ lecturers. However, 67(22.5\%) were assistant professor, 45(15.1\%) were teaching assistants, $18(6 \%)$ were associate professor and $8(2.7 \%)$ were professors in this study. Job experience descriptive statistics indicated that majority 134(45\%) of respondents have 1-4 years' job experience; however, $81(27.2 \%)$ respondents have 5-9 years of job experience. Stratified propionate sampling was used to select the sample.

\subsection{Procedure}

For data analysis purpose SPSS and AMOS (Version 22) is used. There are different steps in the analysis phase. In the first step, data screening have been done in order to check the missing values. It includes descriptive statistics, normality, homogeneity, and correlation analysis.

\subsection{Measurement Model}

With the purpose to conclude the internal reliability of variables, the Cronbach's alphas with factor loading values have been measured by utilizing SPSS. The edge value of the Cronbach's alpha value should be 0.70 or greater than 0.70 for all constructs. Thus, as provided by the table 1 all values of Cronbach's alpha are above than 0.70 . So it is evidenced that all the included variables have fulfilled the reliability issue.

Table 1: Cronbach's alphas with factor loading

\begin{tabular}{|c|c|c|c|c|}
\hline $\begin{array}{l}\mathbf{S} \\
\#\end{array}$ & Variables & $\begin{array}{l}\text { Cronba } \\
\text { ch's } \alpha\end{array}$ & $\begin{array}{l}\text { No. } \\
\text { Item } \\
\text { S }\end{array}$ & Factor loading \\
\hline 1 & $\begin{array}{l}\text { Abusive } \\
\text { supervision }\end{array}$ & .844 & 14 & $\begin{array}{l}0.60,0.60,0.75,0.77,0.81,0.82,0.82,0.74,0.66,0.73,0.7 \\
10.76\end{array}$ \\
\hline 2 & $\begin{array}{l}\text { Employee } \\
\text { creativity }\end{array}$ & .870 & 11 & $0.77,0.63,0.79,0.70,0.63,0.72,0.78,0.72,0.71,0.73$ \\
\hline 3 & $\begin{array}{l}\text { Knowledge } \\
\text { sharing }\end{array}$ & .835 & 8 & $0.80,0.75,0.67,0.71,0.72,0.70$ \\
\hline
\end{tabular}

Sukkur IBA Journal of Management and Business - SIJMB | Volume 4 No. 2 July - December 2017 @ Sukkur IBA University 
The next phase is to decide the convergent on the discriminate reliability of measures utilized. Fornell and Larcker (1981) Stated that three stages process are used to check the validity concerns. First, all the factor loading values ought to be greater than 0.50 which has been proved by the existing framework. Secondly, the composite reliability of all variables ought to be greater than 0.50. Farrell (2010) Stated that composite reliability was anticipated method used to determine the standard reliability of accrual of heterogeneous but related measures. So critical ratio (CR) measures have been used to affirm internal consistency of variables along with its dimensions. The $\mathrm{CR}$ values were $\mathrm{AS}=0.933, \mathrm{EC}=0.914, \mathrm{KS}=0.870$ and all values are greater than 0.5 which satisfy all validity of scales. Moreover, with the aim to conclude discriminate validity, Hair Jret al., (2010) suggested that average variance extracted (AVE) ought to be greater than 0.5 (minimum level). The attained results of AVE values lie between the ranges of 0.528 to 0.541 that is greater than 0.5 which is minimum level and approve the discriminate validity of current study variables shown in Table 2 below.

Table 2: Composite Reliability

\begin{tabular}{llllllll}
\hline & CR & AVE & MSV & ASV & AS & EC & KS \\
\hline AS & 0.933 & 0.541 & 0.020 & 0.011 & 0.157 & & \\
& & & & & & & \\
EC & 0.914 & 0.517 & 0.294 & 0.148 & -0.043 & 0.719 & \\
KS & 0.870 & 0.528 & 0.294 & 0.157 & 0.142 & 0.542 & 0.726 \\
\hline
\end{tabular}

After reliability checking out of the objects, the focal point is to measure the convergent along with discriminate validity and reliability thus relying on CFA (Goodness of fit measurement model).

\subsection{Goodness of fit.}

Table 3: Summary of goodness of fit

\begin{tabular}{lccccccc}
\hline $\begin{array}{l}\text { Fit } \\
\text { Indices }\end{array}$ & x2(df) & p-value & GFI & $\begin{array}{c}\text { AGFI } \\
\text { TLI }\end{array}$ & CFI & $\begin{array}{l}\text { RMSEA } \\
\text { CMIN/DF }\end{array}$ \\
\hline Value & 996.92 & .000 & 0.871 & 0.845 & 0.899 & 0.077 & 2.97 \\
& & & & 0.920 & & & \\
$\begin{array}{l}\text { Suggested } \\
\text { value }\end{array}$ & & $<.05$ & $>.80$ & $>.80$ & $>.90$ & $<.07$ or $<.10$ & $>.90$ \\
\hline
\end{tabular}

The suggested model for the research study represents significant results and the output obtained from AMOS which is model fit indices shows reasonable fit for gathered and analyzed data. The values presented in current research fulfill the criteria of best fit. The chi- square value (df) value along with $\mathrm{p}$ significant value of 996.92(336), $\mathrm{p}=.000$ and other fit indices. According to Bollen (1989) the CFI value needs to be greater than .80 , and in presents study, the value is $0.899(\mathrm{CFI}=0.899)$. 
Moreover, RMSEA value should be $<.07$ or $<.10$ (Hair Jr et al., 2010; Kline, 2011) in the present study its value is $0.077<.10$. According to Baumgartner and Homburg (1996) the value of goodness of fit index (GFI) and aggregated goodness of fit index (AGFI) should be greater than .80 and in the present study the values were .871 and .845 respectively.

Furthermore, the value of Tucker-Lewis co-efficient (TLI) must be >0.9 Kline (2011) which are $.920>0.9$ for the current study. According to Carmines and McIver (1981) the value of CMIN/DF is in the range of 2 to 1 and 1 to 3 are an acceptable fit so in the present study the value of $\mathrm{CMIN} / \mathrm{DF}=2.97$ which shows the model is fit. So these all values fulfill the criteria of goodness of fit model. So it is concluded that the hypothesized model provides a suitable model for analysis. Furthermore, the results of the study verify that the convergent as well as discriminate validity issue has been fulfilled.

\subsection{Structural equation modeling (SEM)}

After accessing and acquiring the satisfactory fit indices of measurement models the next step is to run SEM to test the hypothesized relations between variables. Byrne (2010) stated that SEM displays the association among variables that shows the path analysis between variables underused. The model suggested in this study measures the effect of abusive supervision on the creativity of academic staff. The fundamental associations identified in the hypothesis $(\mathrm{H} 1-\mathrm{H} 4)$ and standardized regression weights of identified model and p-value are utilized to measure the significance of these hypotheses. That was confirmed by the depiction of structural equation modeling. The analysis expedites with the results appropriateness determination and hypothesis testing. All the acquired results linked with the hypothesis directed to the approval of involved hypothesis composed a popularity of causal linkage among variables after observation.

Table 4: Path Analysis Obtained from Structured Equation Modeling

\begin{tabular}{|c|c|c|c|c|c|}
\hline & & Estimate & S.E. & Standardized $\beta$ & $\mathbf{P}$ \\
\hline AS & $<---\mathrm{EC}$ & -.118 & .055 & -2.134 & .033 \\
\hline AS & $<---\mathrm{KS}$ & -.100 & .047 & -2.102 & .036 \\
\hline KS & $<--$ EC & .553 & .071 & 7.780 & $* * *$ \\
\hline
\end{tabular}

\subsection{Hypothesis testing}

The regression standardized weights with values of standard error represents the significance of the understudy variables. The results of the study prove that Abusive supervision (AS) has significant negative effect on Employee Creativity (EC) along with values (Standardized $\beta=-2.134$, S.E $=.055, \mathrm{p}<0.05(0.03<0.05)$ that supports H1. 
Second, results values shows that Abusive supervision (AS) has significant negative effect on Knowledge sharing (KS) with values (Standardized $\beta=-2.102$, S.E=.047, $\mathrm{p}<0.05(0.03<0.05)$ that support $\mathrm{H} 2$ to be true and further proves that abusive supervision decrease knowledge sharing intention. Furthermore, results represent that knowledge sharing has significant positive effect on employee creativity with values (Standardized $\beta=7.780, \mathrm{~S} . \mathrm{E}=.071, \mathrm{P}<0.001$ ) that prove $\mathrm{H} 3$ to be true.

\subsection{Mediation Analysis}

In the analysis, the next step is to determine the mediation relationship hypothesis. In this regard, four-step methods have been used (Baron \& Kenny, 1986). According to Baron and Kenny (1986) there are three types of mediations including full mediation, partial mediation, and no mediation. Three paths are connected with direct effects where one path is connected with indirect effect. These paths include effects of independent towards dependent, the effect of independent towards mediator, the effect of mediator towards dependent and the effect of independent on dependent through the mediator. In a case where direct and indirect effects both are significant, the partial mediation exists, and in a case where indirect effects are insignificant and direct effects is significant the full mediation exists.

Table 5: Direct and Indirect Effects

\begin{tabular}{lll}
\hline Direct Effects & Standardized & Unstandardized \\
\hline $\mathrm{AS} \rightarrow \mathrm{EC}$ & $-.122 * *$ & $-.100 * *$ \\
$\mathrm{AS} \rightarrow \mathrm{KS}$ & $-.142 * *$ & $-.118 * *$ \\
$\mathrm{KS} \rightarrow \mathrm{EC}$ & $0.610 * * *$ & $0.047 * *$ \\
Indirect Effects & & \\
& Standardized & Unstandardized \\
$\mathrm{AS} \rightarrow \mathrm{KS} \rightarrow \mathrm{EC}$ & $-.031^{* *}$ & $0.048 *$ \\
\hline Note: $*=\mathrm{p}<0.05, * *=\mathrm{p}<0.01, * * *$ & $\mathrm{P}<0.001$ &
\end{tabular}

\subsection{Conditions}

The results presented in above Table 4 prove that Knowledge sharing (KS) partially mediate the relationship between AS and EC by fulfilling the direct and indirect paths effect. This is proved by significant effects of AS on EC values of $(\beta=-.122, p<0.01)$, significant effect of AS on KS (independent on mediator) along with values $(\beta=-.142$, $\mathrm{p}<0.01$,); KS on EC (mediator on dependent) with values $(\beta=0.610, \mathrm{p}<0.01)$ and AS shows significant effect on EC through mediator KS with values $(\beta=-.031, p<0.01)$. Negative signs indicate the negative relations among variables. To get the clearer image of the indirect effects constructs over each other the bootstrapping of 2000 samples were also used. The above-mentioned table shows the results of bootstrapping which further support the $\mathrm{H} 4$ that determine that knowledge sharing mediates the relationship between abusive supervision and employee creativity. In the present study, partial mediation exists because both direct and indirect effects are proved to be significant. 
Table 6: Hypothesis status

\begin{tabular}{lll}
\hline Reno & Hypothesis & Status \\
\hline 1 & AS has a significant negative effect on EC. & Accepted \\
2 & AS has a significant negative effect on KS. & Accepted \\
3 & KS has significant positive effect on EC & Accepted \\
4 & AS and EC partially mediated by KS. & Accepted \\
\hline
\end{tabular}

\section{Limitations of the study}

Regardless of the contribution of the portfolio made by this research in practical and theoretical aspects. There is some limitation regarding the size of the sample and the generalization of the investigation. This study also has some limitations that can be incorporated in the future research. The limitations that the platform offers to the future researchers are the following. This study is carried out only in three public sector universities in Lahore, so it is not a comparative study. Generalizability of this research is small since information for this examination was gathered from a solitary division and from single city; the future researcher may collect data from multiple sectors and cities. The results of the study can not be generalized to another sector due to the absence of diverse geographical locations. This study is carried out at the individual level, but it can also be implemented at the team level. Data is collected through questionnaires from academic staff, the future researchers can use multiple approaches to collect data from multiple respondents, such as managers, bank employees and frontline employees. In addition, the present study may be replicable in different sectors and different countries as well.

\section{Discussion and conclusions}

The main objective of this study is to investigate the effect of abusive supervision on the creativity of academic staff in public sector universities. In addition, the current research emphasizes the role of mediation by the direct and indirect effects of knowledge sharing. The results of this study also support previous studies that abusive supervision negatively affects the creativity of academic staff.

Wilk and Moynihan (2005) argued that there are some resources that are accessible to employees which include characteristics such as capabilities and self-respect, social support from associates, co-workers, directors and others, individual control on the job, and contribution in decision making procedure. At the point where abusive supervision is available, it is likely that these estimated assets will be lost. Initially, abused employees are, by definition, likely to have limited support from employers. Supervisor support is the most helpful and vital social assets in a working environment, absence of supervisor's support could be a basic obstruction to encouraging employees to take part

Sukkur IBA Journal of Management and Business - SIJMB | Volume 4 No. 2 July - December 2017 @ Sukkur IBA University 
in deliberate activity, such as knowledge sharing (Aryee, Chen, Sun, \& Debrah, 2007). In this study we examined, how abusive supervision affects creativity of academic staff. First, we found that abusive supervision negatively affected creativity of academic staff. Second, there was an evidence that abusive supervision is also negatively related to knowledge sharing. Third, knowledge sharing was positively related to employee creativity. Last, we found that knowledge sharing partially mediated the relationship between abusive supervision and employee creativity. According to the assumption related to abusive supervision, it is found that abusive supervision leads to lower the knowledge sharing behavior of employees. Because when employees face abusive supervisory behavior, they can resist knowledge sharing. When employees encounter abusive supervision they tend to avoid knowledge sharing. In this way, the research findings were found in the trajectory of previous results that represented a negative association between abusive supervision and knowledge sharing (Aryee et al., 2007; Lee et al., 2013).

\section{References}

Alreck, P. L., \& Settle, R. B. (1985). The survey research handbook. Homewood, Illinois: Richard D. Irwin. Inc, 13(1), 71-73.

Amabile, T. M. (1996). Creativity in Context. Boulder, Colorado: Westview Press Inc.

Amabile, T. M., Schatzel, E. A., Moneta, G. B., \& Kramer, S. J. (2004). Leader behaviors and the work environment for creativity: Perceived leader support. The Leadership Quarterly, 15(1), 5-32.

Aryee, S., Chen, Z. X., Sun, L.-Y., \& Debrah, Y. A. (2007). Antecedents and outcomes of abusive supervision: test of a trickle-down model. Journal of Applied Psychology, 92(1), 191.

Baron, R. M., \& Kenny, D. A. (1986). The moderator-mediator variable distinction in social psychological research: Conceptual, strategic, and statistical considerations. Journal of personality and social psychology, 51(6), 1173.

Baumgartner, H., \& Homburg, C. (1996). Applications of structural equation modeling in marketing and consumer research: A review. International journal of Research in Marketing, 13(2), 139-161.

Bock, G.-W., Zmud, R. W., Kim, Y.-G., \& Lee, J.-N. (2005). Behavioral intention formation in knowledge sharing: Examining the roles of extrinsic motivators, social-psychological forces, and organizational climate. MIS quarterly, 87-111.

Bollen, K. A. (1989). A new incremental fit index for general structural equation models. Sociological Methods \& Research, 17(3), 303-316.

Byrne, B. M., \& Van de Vijver, F. J. (2010). Testing for measurement and structural equivalence in large-scale cross-cultural studies: Addressing the issue of nonequivalence. International Journal of Testing, 10(2), 107-132.

Chang, Y.-Y., Gong, Y., \& Peng, M. W. (2012). Expatriate knowledge transfer, subsidiary absorptive capacity, and subsidiary performance. Academy of management journal, 55(4), 927-948. 
Duffy, M. K., Ganster, D. C., \& Pagon, M. (2002). Social undermining in the workplace. Academy of management journal, 45(2), 331-351.

Farrell, A. M. (2010). Insufficient discriminant validity: A comment on Bove, Pervan, Beatty, and Shiu (2009). Journal of Business Research, 63(3), 324-327.

Fornell, C., \& Larcker, D. F. (1981). Evaluating structural equation models with unobservable variables and measurement error. Journal of marketing research, $39-50$.

Foss, N. J., Husted, K., \& Michailova, S. (2010). Governing knowledge sharing in organizations: Levels of analysis, governance mechanisms, and research directions. Journal of Management studies, 47(3), 455-482.

French, J. R., Raven, B., \& Cartwright, D. (1959). The bases of social power. Classics of organization theory, 7, 311-320.

Hair Jr, J., Black, W., Babin, B., \& Anderson, R. (2010). Multivariate Data Analysis; a global perspective (ed.): Pearson Education Inc. New Jersey, USA, 5.

Hon, A. H. (2013). Does job creativity requirement improve service performance? A multilevel analysis of work stress and service environment. International Journal of Hospitality Management, 35, 161-170.

Hon, A. H., \& Lu, L. (2015). Are we paid to be creative? The effect of compensation gap on creativity in an expatriate context. Journal of World Business, 50(1), 159-167.

Janssen, O. (2003). Innovative behaviour and job involvement at the price of conflict and less satisfactory relations with co-workers. Journal of occupational and organizational psychology, 76(3), 347-364.

Kline, R. (2011). Principles and Practice of Structural Equation Modeling, 3rd edn Guilford Press. New York.

Lee, S., Yun, S., \& Srivastava, A. (2013). Evidence for a curvilinear relationship between abusive supervision and creativity in South Korea. The Leadership Quarterly, 24(5), 724-731.

Lin, W., Wang, L., \& Chen, S. (2013). Abusive supervision and employee well-being: The moderating effect of power distance orientation. Applied Psychology, 62(2), 308-329.

Liu, D., Liao, H., \& Loi, R. (2012). The dark side of leadership: A three-level investigation of the cascading effect of abusive supervision on employee creativity. Academy of management journal, 55(5), 1187-1212.

Mackey, J. D., Frieder, R. E., Brees, J. R., \& Martinko, M. J. (2017). Abusive supervision: A meta-analysis and empirical review. Journal of management, 43(6), 1940-1965.

Martinko, M. J., Harvey, P., Sikora, D., \& Douglas, S. C. (2011). Perceptions of abusive supervision: The role of subordinates' attribution styles. The Leadership Quarterly, 22(4), 751-764.

Morgan, D. N. (1953). Creativity today: A constructive analytic review of certain philosophical and psychological Work. The Journal of Aesthetics and Art Criticism, 12(1), 1-24. 
Mumford, M. D., Scott, G. M., Gaddis, B., \& Strange, J. M. (2002). Leading creative people: Orchestrating expertise and relationships. The Leadership Quarterly, 13(6), 705-750.

Namie, G., \& Namie, R. (2009). Bully at work: What you can do to stop the hurt and reclaim your dignity on the job: Sourcebooks, Inc.

Noordin, F., \& Jusoff, K. (2009). Levels of job satisfaction amongst Malaysian academic staff. Asian Social Science, 5(5), 122.

Pais, L., \& Santos, N. R. d. (2015). Knowledge-sharing, cooperation, and personal development. The Wiley Blackwell Handbook of the Psychology of Training, Development, and Performance Improvement, 278-302.

Rusly, F., Yih-Tong Sun, P., \& L. Corner, J. (2014). The impact of change readiness on the knowledge sharing process for professional service firms. Journal of Knowledge Management, 18(4), 687-709.

Ryhammar, L., \& Brolin, C. (1999). Creativity research: Historical considerations and main lines of development. Scandinavian journal of educational research, 43(3), 259-273.

Serrat, O. (2017). Harnessing creativity and innovation in the workplace Knowledge Solutions (pp. 903-910): Springer.

Shalley, C. E., Zhou, J., \& Oldham, G. R. (2004). The effects of personal and contextual characteristics on creativity: Where should we go from here? Journal of management, 30(6), 933-958.

Tabachnick, B. G., \& Fidell, L. S. (2001). Using multivariate analysis.

Tepper, B. J. (2000). Consequences of abusive supervision. Academy of management journal, 43(2), 178-190.

Tepper, B. J., Duffy, M. K., Henle, C. A., \& Lambert, L. S. (2006). Procedural injustice, victim precipitation, and abusive supervision. Personnel Psychology, 59(1), 101-123.

Tepper, B. J., Moss, S. E., \& Duffy, M. K. (2011). Predictors of abusive supervision: Supervisor perceptions of deep-level dissimilarity, relationship conflict, and subordinate performance. Academy of management journal, 54(2), 279-294.

Tierney, P. (2008). Leadership and employee creativity. Handbook of organizational creativity, 95123.

Wang, S., \& Noe, R. A. (2010). Knowledge sharing: A review and directions for future research. Human resource management review, 20(2), 115-131.

Wilk, S. L., \& Moynihan, L. M. (2005). Display rule" regulators": the relationship between supervisors and worker emotional exhaustion. Journal of Applied Psychology, 90(5), 917.

Zhang, H., Kwan, H. K., Zhang, X., \& Wu, L.-Z. (2014). High core self-evaluators maintain creativity: A motivational model of abusive supervision. Journal of management, 40(4), 1151-1174.

Zhou, J., \& Shalley, C. E. (2003). Research on employee creativity: A critical review and directions for future research Research in personnel and human resources management (pp. 165-217): Emerald Group Publishing Limited. 